\title{
Prioritizing Apple Production Constraints in Sinan Woreda, Ethiopia:A Constraint Facing Index (CFI) Approach
}

\author{
Mekonnen Salele \\ Federal Urban Job Creation and Food Security Agency, Addis Ababa, Ethiopia \\ Tsegaye Molla* \\ Department of Agricultural Economics, Debre Markos University, Ethiopia
}

\begin{abstract}
Identifying and tackling apple production constraints is a demanding development intervention towards ensuring food security and livelihood diversification. This study finds out and prioritized apple production constraints among apple producer farmers in Sinan Woreda. Data is collected from a sample of 214 apple farmers and the data is subjected to Constraint Facing Index (CFI) analysis developed for setting future research and development priorities thereby supporting policy making and practices. Accordingly; lack of practical skill $(\mathrm{CFI}=425)$, management problems $(\mathrm{CFI}=150)$, the high price of apple seedling $(\mathrm{CFI}=103)$, and shortage of water $(\mathrm{CFI}=$ 80 ), are the top four constraints of apple growers requiring policy makers and practitioners to target in a priority setting strategy.
\end{abstract}

Keywords: Apple, Apple production constraints, Constraint Facing Index (CFI), Sinan

DOI: $10.7176 / \mathrm{JAAS} / 68-01$

Publication date:September $30^{\text {th }} 2020$

\section{Introduction}

Apple is the world's deciduous fruit which accounts for 50\% of fruit tree production globally putting China at the front of the world's apple producing country; followed by USA, India, and Turkey. The leading producer of Apple in Africa is South Africa followed by Egypt and Kenya (USDA, 2013). Ethiopia has a comparative advantage in a number of horticultural commodities due to its favorable climate, proximity to European and Middle Eastern markets and cheap labor (EIA, 2012). However, the production of horticultural crops is much less developed than the production of food grains in the country. The country has still the potential to export apple, if production and quality is further improved. Hence, in Ethiopia great potential exists for temperate fruits (Seifu et al., 2014) to contribute to economic development and poverty alleviation by improving the living standard of the poor farmers in addition to the environmental sustainability aspects. Government organization (GOs) and non-government organizations (NGOs) are contributing their share in the enhancement of household-based food security through integrated rural development. Apple is a perennial crop, which stays productive for over many years. If farmers are accessing high yielding and high value crops, they can improve the cash income of poor farmers, provide rich sources of vitamins and minerals, nourishes the diet of the family and plays a role in developing a healthy and productive community. An increase in the coverage of Apple plantations contributes a vital role in modifying the environment. A total apples seedling distributed is 43,899 disaggregated by individual household as 25,788 ; by cooperatives 7,100; government supplying 5,310 seedlings; and non-government organizations 5,701 seedlings (SWADO, 2008).

Of the $45 \%$ landmass of Ethiopian highland, $85 \%$ of the population seldom produce apple though it's considered as a temperate fruit by virtue of high altitude (Seifu et al., 2014). As a result, the highland communities are not getting the economic, diet and environmental advantage expected from fruits. As highland fruit, apple is newly introduced in Ethiopia, but the production and management knowledge and skills demanded by the plant is not yet well familiarized among experts. Tamirat and Muluken (2018) indicated that production problems, particularly low-quality fruits are dominating in apple farmers. The current agricultural production system underway is believed to be practiced for the past many centuries.

The need and potential to increase fruit crop production in Ethiopia, particularly in dry land areas is realized while an increasing demand for the fruit is grown in local and urban markets. Therefore, upgrading or scaling up the knowledge, attitude and skill of development agent is very important to tackle the problem of fruit production as wale as efficiency in addition to improve the consumption habit of our farmers. It is hoped that the finding of this study may help and direct future studies. At the center of apple production province in Ethiopia, how to increase apple per unit yield given that priority is given to pressing production challenges are hot issues. In light of these, the specific objective of the study is to identify and prioritize the most pressing challenges of apple production in the study area. 


\section{Research Methodology}

\subsection{Study Area and Sampling Design}

The study is done in Sinan Woreda located in East Gojjam Administrative Zone, Amhara National Regional State, Ethiopia with an altitude ranging from 2800-4088 m.a.s.l. The land use constitutes 7509 ha of grazing land, 5477 ha of forest land, 210 ha of permanent plant, 1320 ha under village and 2440 ha unused land (SWADO, 2007). The total number of sample apple producers is determined by applying a simple formula of Yamane (1967) although there are many options to do so. Multi-stage sampling procedure is employed to select the total number of samples. The first stage involves stratification of 16 rural kebeles of Sinan woreda in to three major agroecological zones (dega, woinadega and wurch) to keep sample representativeness. All rural kebeles within each stratum were listed out with the help of district extension experts. Then, a total of three kebeles (yeted, gedamawit and zilan) representing the aforementioned agro-ecological zones were selected randomly in proportion to the area coverage of the agro-ecologies stratification of apple growers and non-growers. Finally, after identifying the sampling frame which contains the complete list of apple grower farmers within each selected kebele with kebele leaders, a total of 214 sample apple producer farmers are randomly by simple random sampling method selected from the selected kebeles in proportion to their total number of households.

$$
n=\frac{N}{1+N(e)^{2}}
$$

Where $\mathrm{n}$ is the sample rural household, $\mathrm{N}$ is the total rural households (467 households) within the selected three kebeles of the woreda, and e is the level of precision set at $5 \%$.

\subsection{Method of Data Analysis}

Following Farouque and Takeya (2007) and Faruq (2008), farmers are allowed to mention constraints related with apple production during the pilot survey. The constraints are then organized using constraints confrontation scale interview schedule. The respondents were asked to give their response as 'high', 'medium', 'low' and 'not at all' for each constraint included in constraint confrontation scale based on their extent of constraint confrontation in apple production. The weights for 'high', 'medium', 'low' and 'not at all' responses were assigned 3, 2, 1 and 0 respectively. To ascertain extent of seriousness of constraints 'Constraint Facing Index (CFI) for each of the constraints was computed. Constraints were then ranked according to their CFI value. Based on analytical procedure, 12 constraints were identified, given ranks, and priority intervention forwarded thereof. The following Constraint Facing Index (CFI) formula is developed to rank constraints of apple producer farmers meaningfully for concerted intervention in the future based on seriousness of the constraint:

\section{Constraint Facing Index $(\mathrm{CI})=\mathrm{NH} \times 3+\mathrm{NM} \times 2+\mathrm{NL} \times 1+\mathrm{NN} \times 0$}

Where: $\mathrm{NH}=$ Number of farmers who responded high constraint

$\mathrm{NM}=$ Number of farmers who responded medium constraint

$\mathrm{NL}=$ Number of farmers who responded low constraint

$\mathrm{NN}=$ Number of farmers who responded not at all a constraint

\section{Results and Discussion}

\subsection{Description of Sample Households}

Most apple producer farmers are in the economically productive age group on average 45 years, family size of 5 persons per head, and with average livestock holding of 5.1 TLU, contacted extension workers 23 times per year (Table 1). The significantly low extension contacts they get per annum may attribute to their pressing need to acquire more shared experiences to learn practical skills of apple production as top constraint. About $45 \%$ of the farmers found to get the chance to read and write from their adult education experiences (Table 2).

Table 1. Description of Household Characteristics

\begin{tabular}{|l|l|l|l|l|l|}
\hline Variable & Obs & Mean & Std. Dev. & Min & Max \\
\hline Age & 214 & 45.18692 & 11.86713 & 1 & 83 \\
\hline Family size & 214 & 5.224299 & 1.696771 & 2 & 10 \\
\hline Livestock holding & 214 & 5.097911 & 2.176032 & .001 & 12.18 \\
\hline Extension per year & 214 & 23.19159 & 18.01136 & 1 & 58 \\
\hline
\end{tabular}

Source: Field survey data, 2018 
Table 2. Distribution of Sample Households by Education Status

\begin{tabular}{|l|l|l|}
\hline Education & Freq. & $\%$ \\
\hline Grade 1-10 & 46 & 21.50 \\
\hline Grade 11-12 & 1 & 0.47 \\
\hline Degree and above & 4 & 1.87 \\
\hline Not read and write & 41 & 19.16 \\
\hline Read and write & 18 & 8.41 \\
\hline Adult education & 98 & 45.79 \\
\hline Religious education & 6 & 2.80 \\
\hline
\end{tabular}

Source: Field survey data, 2018

\subsection{Constrains of Apple Production}

As shown in (Table 3), it is indicated that 'lack of skill and knowledge' to be productive in apple with rank of first $(\mathrm{CFI}=425)$ followed by 'Management problem' $(\mathrm{CFI}=150)$, 'High Price of seedling' with rank of third place $(\mathrm{CFI}=103)$, and 'shortage of ran/water' $(\mathrm{CFI}=80)$ with fourth rank are the top four priority challenges aggregated from apple producer farmers. Hence, the office of Agricultural Extension (horticultural division), plant science team, agricultural cooperatives, marketing agents, and irrigation bureaus need to take the initiatives to solve farmers' constraints in a synergic and concerted strategy. Putting differently, the respective problem-solving institutions should set priority and work synergistically to make apple production constraints solved through time. Table 3. Frequency distribution of apple farmers' constraints in order of importance

\begin{tabular}{|l|l|c|c|c|c|c|c|}
\hline \multirow{2}{*}{ S/n } & \multirow{2}{*}{ Constraints of Apple Production } & & & & & & \\
\cline { 3 - 8 } & & High & Medium & Low & Not at all & CFI & Rank \\
\hline 1 & Lack of skill & 121 & 26 & 10 & 0 & 425 & $1^{\text {st }}$ \\
\hline 2 & Management problem & 2 & 51 & 42 & 0 & 150 & $2^{\text {nd }}$ \\
\hline 3 & High price of seedling & 29 & 7 & 2 & 0 & 103 & $3^{\text {rd }}$ \\
\hline 4 & Shortage of rain/water & 6 & 9 & 44 & 0 & 80 & $4^{\text {th }}$ \\
\hline 5 & Low seedling varieties & 2 & 30 & 13 & 0 & 79 & $5^{\text {th }}$ \\
\hline 6 & Lack of extension agents support & 3 & 16 & 10 & 0 & 51 & $6^{\text {th }}$ \\
\hline 7 & Lack of credit & 1 & 16 & 13 & 0 & 48 & $7^{\text {th }}$ \\
\hline 8 & Water logging & 2 & 2 & 14 & 0 & 24 & $8^{\text {th }}$ \\
\hline 9 & High weed infestation & 0 & 3 & 16 & 1 & 22 & $9^{\text {th }}$ \\
\hline 10 & High apple disease \& pest & 4 & 2 & 3 & 0 & 19 & $10^{\text {th }}$ \\
\hline 11 & Low fertility of the soil & 0 & 1 & 1 & 1 & 3 & $11^{\text {st }}$ \\
\hline 12 & Flooding & & & 1 & 0 & 15 & $12^{\text {th }}$ \\
\hline
\end{tabular}

Note: $\mathrm{CFI}=$ Constraint Facing Index

As a priority setting evidence (Figure 1) much of the constraints apple producers face require directing resources (be it financial or labor) to solving the first four top apple production constraints. This may require devoting resources for research and development and renovating solutions towards maximization of apple productivity and efficiency. Any apple production and management programs and projects need to reconsider their interventions to target against the aforementioned prioritized constraints taking the top four problems that farmers are facing. 


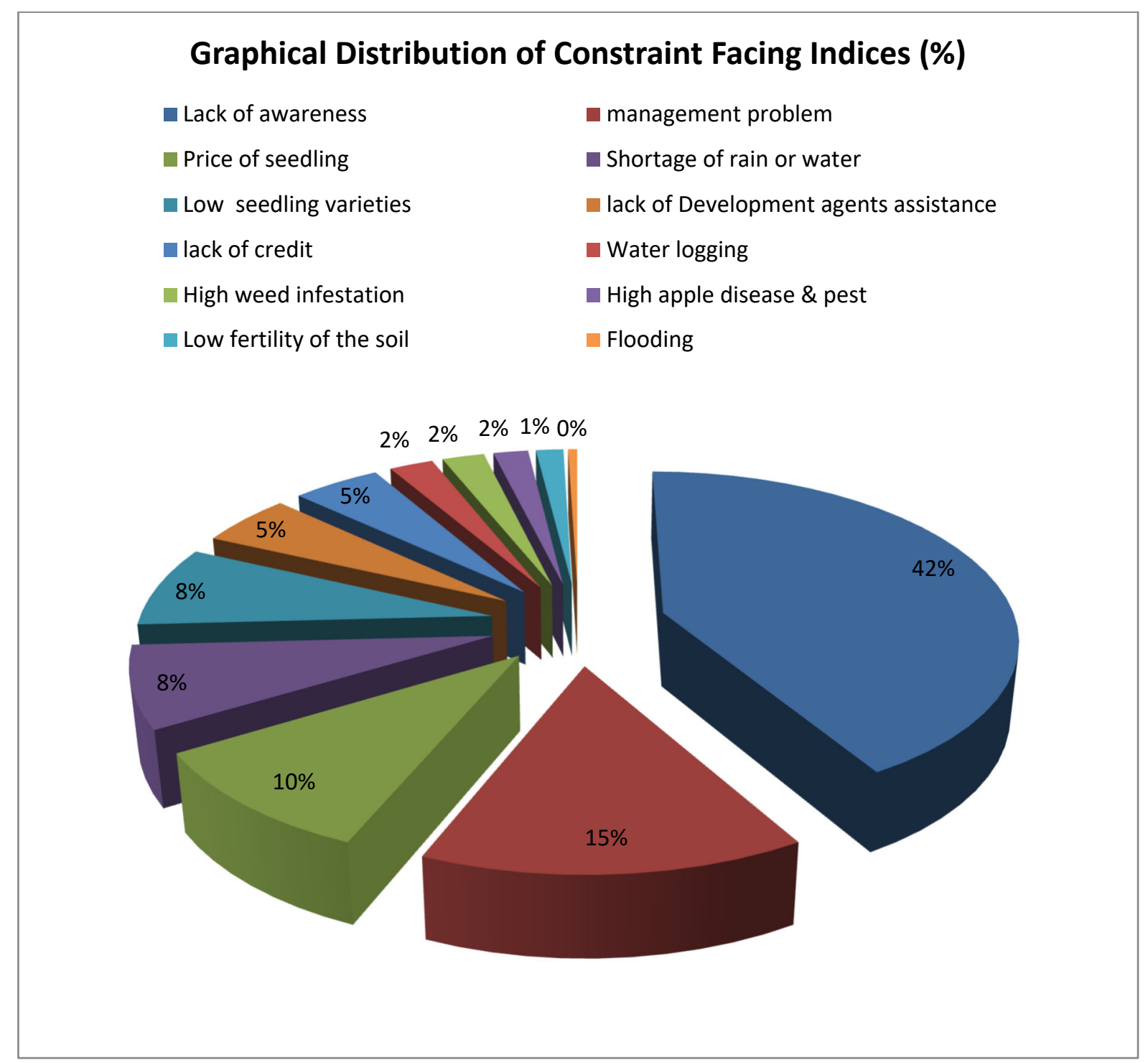

Figure 1. Apple Production constraints in ranked order (Author, 2018)

\section{Conclusion}

It is worth emphasizing that this study attempted to document and pinpoint the overall challenges of apple production. Accordingly, constraints emanating from production skills, management problems, and market bases are significant problems reflected by the apple farming communities with ranked order of first and second using constraint facing index analysis. The indicated top four problems are felt by farmers as their frequent problems in apple production.

\section{Policy Suggestions}

Agricultural policy makers and practitioners should work closely towards minimization of challenges related with apple production namely: innovating productivity enhancing apple technologies, disease resistant variety release, and seedling distribution with minimum cost are worth mentioning. The results further indicate priority setting is required to give prior policy agenda and then targeting against the top four prioritized production and marketing constraints of apple producer farmers. Priority targeting at the most serious constraints limiting production and marketing efficiency will be more realistic if agricultural programs and projects reconsider their future interventions to work closely with more synergy towards higher apple productivity and efficiency.

\section{References}

Ethiopian Investment Agency (EIA). (2012). Investment Opportunity Profile for the Production of Fruits and Vegetables in Ethiopia.

Farouque, G., and Takeya, H., (2007). Resource-Poor Farmers' Constraints regarding Integrated Soil Fertility and 
Nutrient Management for Sustainable Crop Production: A farm level study in Bangladesh.https://ideas.repec.org/p/ags/eaa106/7917.html

Faruq Hasan M. 2008. Economic Efficiency and Constraints of Maize Production in the Northern Region of Bangladesh. j.innov.dev.strategy 1(1): 18-32. http://ggfjournals.com/content/papers/dsv2i118-32

Seifu, F., Sabura, S., Agena, A., Guchie, G., Fantahun, W., and Belete, Y., (2014). Survey on Apple Production and Variety Identification in Chencha District of Gamo Gofa Zone, Southern Ethiopia. J. Agric. Food. Tech., 4(5)7-15, 2014. https://www.textroad.com/pdf/JAFT/J.\%20Agric.\%20Food.\%20Tech.,\%204(5)715,\%202014.pdf

SWADO, (2007). Sinan Woreda Bureau of Agricultural Development Office, Annual Report of 2007.

SWADO, (2008). Sinan Woreda Bureau of Agricultural Development Office, Annual Report of 2008.

Tamirat, G; Muluken, P (2018). Analysis of Apple Fruit Value Chain in Southern Ethiopia; the Case of Chencha District. Greener Journal of Plant Breeding and Crop Science, 6(3), 26-34: http://doi.org/10.15580/GJPBCS.2018.3.100218043

Yamane, T., 1967. Statistics, An Introductory Analysis, ${ }^{\text {nd }}$ Edition. New York.

United States Department of Agriculture (USDA) (2013). Fresh Apples, Grapes and Pears: World Markets and Trade. A study report by USDA, USA. 